\title{
NUMERICAL ANALYSIS ON INFLUENCE OF VARIOUS
}

\section{PARAMETERS AND THEIR INTERACTIONS ON}

\section{DRAWABILITY OF CYLINDRICAL CUPS}

\author{
P. V. R. RAVINDRA REDDY ${ }^{1} \&$ A. A. SRIRAMAKRISHNA ${ }^{2}$ \\ ${ }^{I}$ Professor, Department of Mechanical Engineering, CBIT, Gandipet, Hyderabad, India \\ ${ }^{2}$ Associate Professor, Department of Mechanical Engineering, CBIT, Gandipet, Hyderabad, India
}

\begin{abstract}
Deep drawing is a complex process that is influenced by various parameters like tooling configurations, blank configurations, material properties, and forming conditions. Limit Drawing Ratio and limit strains are two parameters to indicate the draw ability of the material. In this paper, the effect of various parameters like die and punch corner radii, clearance, blank holding force, friction coefficient between die and punch, punch diameter on limit drawing ratio is investigated and presented by using an explicit finite element code LSDYNA 3D. The model is validated by comparing force obtained by the existing experimental setup with the one obtained with simulation. Initial estimation of the effect of the parameters listed above and their interactions is found out by using two levels L8 orthogonal array. After identifying the most effective parameters, their effect on the LDR is studied and presented.
\end{abstract}

KEYWORDS: Limit Drawing Ratio (LDR), Orthogonal Arrays \& Column Effect Method

Received: Jan 14, 2018; Accepted: Feb 06, 2018; Published: Mar 06, 2018; Paper Id.: IJMPERDAPR201850

\section{INTRODUCTION}

Deep drawing process is used to manufacture complicated parts from sheet metal and is used in many industries such as automobile, aerospace, appliance and so on. The process design of the deep drawing process involves so many parameters such as tooling configurations, blank configurations, material properties, and forming conditions, thereby involving a lot of trial and error runs which increase not only the cost of development but also the time to market. Therefore, systematical design and process simulations have presented themselves as a vital part in today's competitive systems.

Drawability is defined as the ability to draw the blanks into cups of desired shape without any defects and is difficult to be quantified. One of the parameters which indicate the drawability is the limit drawing ratio, which is the ratio of the maximum blank diameter to the cup diameter at the onset of tearing. The limit drawing ratio is usually limited by the maximum allowable drawing force at the beginning of the punch nose rounding, when punch nose radius is not too great and appreciable stretching over the punch nose done not take place [1] 


\section{Finite Element Model \& Experimental Validation}

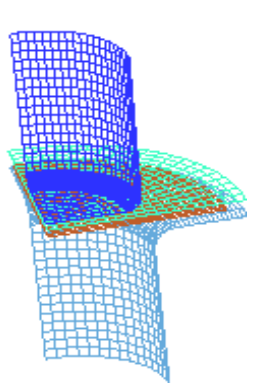

Figure1: Finite element model

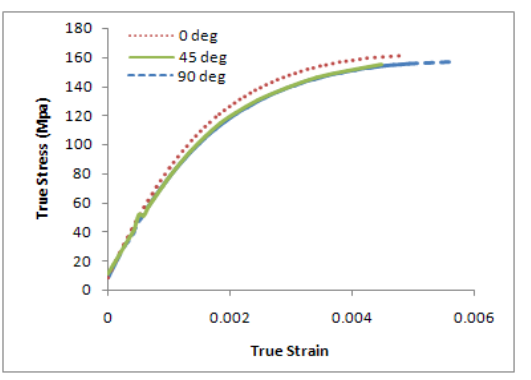

Figure 2: True Stress-Strain Diagrams of Specimens at $0^{0}, 450$ and 900 to Rolling Direction

Initially an FEA Model (Figure 1) is created in the existing setup of punch, die, blank and blank holder for which the comparison of force obtained from the simulation with the experimental result. The existing set up is designed to produce a $25 \mathrm{~mm}$ cup from a $45 \mathrm{~mm}$ blank. Based on the symmetry boundary condition, a quarter of the geometry is modeled by using a Hyper mesh with LSDYNA template. The punch presses the sheet into the die cavity. In sheet metal forming, generally, membrane element or continuum element or shell elements are employed [2]. Since membrane elements lack the bending stiffness and the continuum element takes higher computation time, the blank is modeled with shell elements of the mid plane with Belytschko formulation and with five integration points. Punch, die and blank holder are taken as rigid materials and for obtaining material model of the blank material

Tensile test specimens of ASTM Standard size are prepared from the commercial pure Aluminum, AA1100, sheet. The pieces are cut in the rolling direction, $45^{\circ}$ to rolling direction and in transverse to the rolling direction The pieces are tested at AMTL (Aero Space Material testing Laboratory), A division of MIDHANI, DRDO on a universal testing machine (INSTRAN 4507 MODEL). The true stress and strains are computed up to the ultimate point and presented in Figure 2.

The material properties obtained for the specimens in three directions are presented in table 1.

Table 1: Material Properties Obtained from the Tensile Test

\begin{tabular}{|c|l|c|c|c|c|}
\hline \multirow{2}{*}{$\begin{array}{c}\text { S. } \\
\text { No }\end{array}$} & \multicolumn{1}{|c|}{ Property } & \multicolumn{4}{c|}{ Value } \\
\cline { 3 - 6 } & & $\mathbf{0}$ & $\mathbf{4 5}$ & $\mathbf{9 0}$ & Average \\
\hline 1. & Yield strength (0.2\% Proof) in Mpa & 142.7 & 138.9 & 134.1 & 138.6 \\
\hline 2. & Ultimate Tensile Strength (Mpa) & 161.3 & 154.7 & 156.6 & 157.7 \\
\hline 3. & Modulus of Elasticity (Mpa) & 57109 & 50908 & 54312 & 54110 \\
\hline 4. & Yield Strain (from values) & 0.002697 & 0.002926 & 0.002667 & 0.002763 \\
\hline 7. & Anisotropic Index (R) & 1.12 & 1.06 & 1.07 & \\
\hline 8. & Planar Anisotropy & \multicolumn{5}{|c|}{1.078} \\
\hline 9. & Normal Anisotropy & \multicolumn{5}{|c|}{} \\
\hline
\end{tabular}

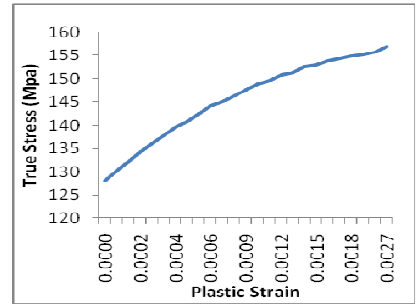

Figure 3: Flow curve of AA1100 
To check the initial anisotropy, the value of the normal anisotropy ' $\bar{R}$ ' is computed and presented in table 1 . It is observed that the value of $\bar{R}$ is slightly more than 1. So initial anisotropy is neglected and the blank is treated to be isotropic, which simplifies the material characterization. . Considering the above the material model 'piece wise linear isotropic plasticity model is selected for analysis for which flow curve is to be input. Since the strain is additively decomposive, the plastic strain ' $\varepsilon^{\mathrm{p}}$ ' can be found out by subtracting elastic strain ' $\varepsilon^{\mathrm{e}}$ ' from the total strain ' $\varepsilon^{\prime}$ '. $\varepsilon^{\mathrm{e}}$ can be found out using the relation $\varepsilon^{e}=\sigma_{y} / E$, Where $\sigma_{\mathrm{y}}$ is the current stress. On obtaining the plastic strain values the curve between true stress and plastic strain is plotted and presented in figure 3. The flow curve obtained in the transverse direction is taken as input, as it is noted from the table that the average properties are nearer to the properties in transverse direction to the rolling direction.

The mesh convergence is checked by the convergence of the punch load by the time for various mesh sizes as done by Jamal Hematian [3].

Experimental validation of the finite element model is carried out by comparing the force obtained by the experiment with force obtained in simulation. The experimental setup as shown in Figure.4 consists of a 25T hydraulic press interfaced to the computer with the load cells through digital force indicator. The blank holding schema obtained from the experimental set up shown figure.5 is applied in the simulation.
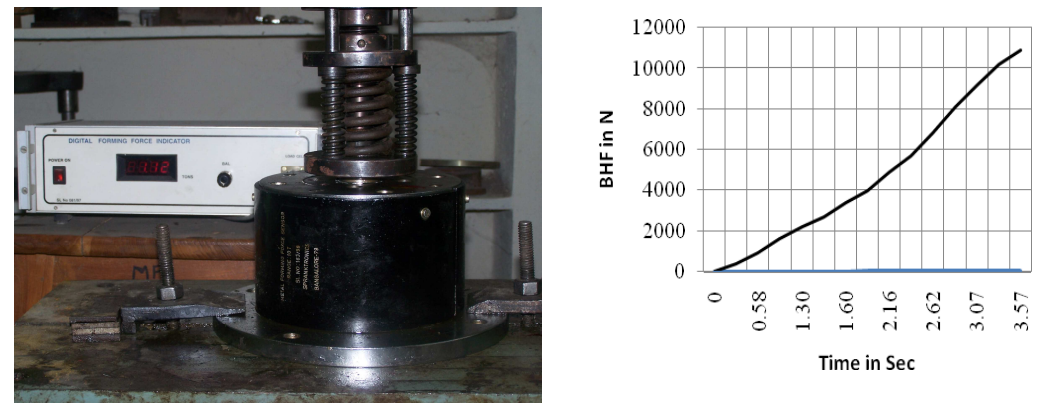

Figure 4: Experimental Set up

Figure 5: BHF Schema Obtained from the Experiment

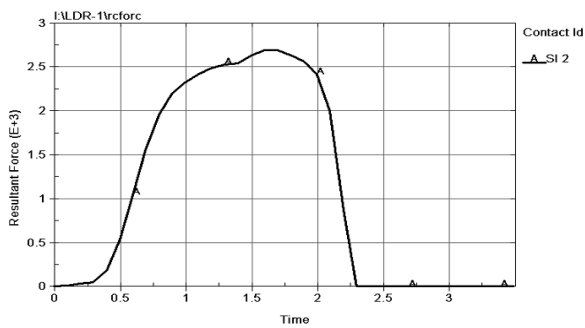

Figure 6: Transient Load v/s Time Diagram obtained from the Experiment

Since it is spring loaded blank holder the schema should be linear. The same is evident from the Figure 5 and the force obtained from the experimental setup is shown in Figure. 6 and by simulation in Figure.7. 


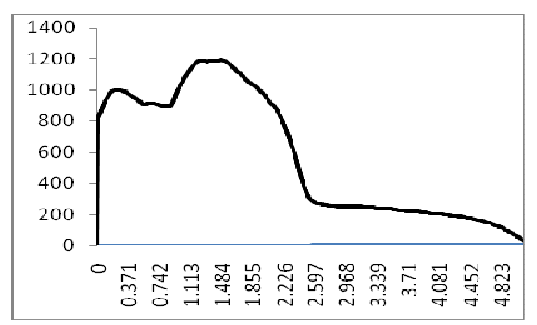

Figure 7: Transient Load v/s Time Diagram obtained from the Simulation

The maximum force obtained from the experiment is $1184 \mathrm{Kg}$. and from the simulation, it is found to be $2697.9 \mathrm{~N}$ i.e $275 \mathrm{Kg}$. Since it is quarter model the actual force obtained from simulation is four times the given value of the simulation i.e $1100 \mathrm{Kg}$. The deviation from the experimental result is $7 \%$. The reason for this discrepancy may be due to non-isotropic hardening during forming operation. The failure occurs when $\sigma_{\text {eff }}=\sigma_{\text {ult }} \quad$ where $\sigma_{\text {eff }}$ and $\sigma_{\text {ult }}$ are von-Mises' effective stress and Ultimate Tensile Strength (110 MPa for AA1100) respectively.

In this work the effect of die profile, punch profile, clearance, friction coefficient, punch diameter on limit drawing ratio is investigated

\section{SIMULATIONS}

After the validation, the simulations are planned following DOE techniques [4],

Since each simulation takes a large amount of computational time. The screening test for the above five factors is planned by considering the factors at two levels. The screening test levels considered are shown table 2. Generally for continuous factors the first level may be the lower of the two values being tested and the second will be the higher.

Table 2: Levels Chosen for Screening Test

\begin{tabular}{|c|l|c|c|}
\hline $\begin{array}{c}\text { S. } \\
\text { No }\end{array}$ & \multicolumn{1}{|c|}{ Factor } & $\begin{array}{c}\text { Level 1 } \\
\text { (Min) }\end{array}$ & $\begin{array}{c}\text { Level 2 } \\
\text { (Max.) }\end{array}$ \\
\hline 1. & Punch Profile & $2 \mathrm{~mm}$ & $5 \mathrm{~mm}$ \\
\hline 2. & Die Profile & $3 \mathrm{~mm}$ & $10 \mathrm{~mm}$ \\
\hline 3. & Clearance & $7 \%$ & $20 \%$ \\
\hline 4. & Friction Coeff. & 0.015 & 0.45 \\
\hline 6. & Punch diameter & $10 \mathrm{~mm}$ & $40 \mathrm{~mm}$ \\
\hline
\end{tabular}

Table 3: L8-Orthogonal Array after Assignment of Factors

\begin{tabular}{|c|c|c|c|c|c|}
\hline \multirow{2}{*}{$\begin{array}{c}\text { Trial } \\
\text { No }\end{array}$} & $\begin{array}{c}\mathbf{R}_{\mathbf{p}} \\
(\mathbf{m m})\end{array}$ & $\begin{array}{c}\mathbf{R}_{\mathbf{d}} \\
(\mathbf{m m})\end{array}$ & $\begin{array}{c}\mathbf{C} \\
\mathbf{\%}\end{array}$ & $\boldsymbol{\mu}$ & $\begin{array}{c}\mathbf{D}_{\mathbf{P}} \\
(\mathbf{m m})\end{array}$ \\
\hline $\mathbf{1}$ & 2 & 3 & 7 & 0.015 & 10 \\
\hline $\mathbf{2}$ & 2 & 3 & 20 & 0.45 & 40 \\
\hline $\mathbf{3}$ & 2 & 10 & 7 & 0.45 & 40 \\
\hline $\mathbf{4}$ & 2 & 10 & 20 & 0.015 & 10 \\
\hline $\mathbf{5}$ & 5 & 3 & 7 & 0.45 & 10 \\
\hline $\mathbf{6}$ & 5 & 3 & 20 & 0.015 & 40 \\
\hline $\mathbf{7}$ & 5 & 10 & 7 & 0.015 & 40 \\
\hline $\mathbf{8}$ & 5 & 10 & 20 & 0.45 & 10 \\
\hline
\end{tabular}

Clearance is generally from $7 \%$ to $14 \%$. H.Gharib et.al [5] has used $20 \%$ clearance with die radius up to $10 \mathrm{~mm}$ for the cylindrical cup of $25 \mathrm{~mm}$ diameter with punch and die profiles of $5 \mathrm{~mm}$ and $10 \mathrm{~mm}$ respectively. M. Jurkovic et.al 

Interactions on Drawability of Cylindrical Cups

[6] have experimentally found out friction coefficients in deep drawing for various surface conditions of tooling at different degrees of deformation. They vary from 0.015 to 0.18 . In case of dry contact, the friction between and $\mathrm{Al}$ and steel is 0.45 for sliding [7]. The above range is selected for the analysis for the present work. An L8 orthogonal array is chosen which has 7 columns and 8 trials. The orthogonal array after factor assignment is shown in Table 3.

\section{RESULTS \& DISCUSSIONS}

As a sample, von-Mise's stresses for various drawing ratios for trial 1 and are presented in Figures from Figure 8 to figure 11 .

The limit drawing ratios for various trials are presented in Table 4. The analysis is being carried out by column effect method. Summation at level $1(\mathrm{~S} 1)$ and the summation at level 2 (S2) are computed and the difference (S1-S2) is found out. According to the column effect method, higher the difference between the two sums, higher is the effect of that parameter.

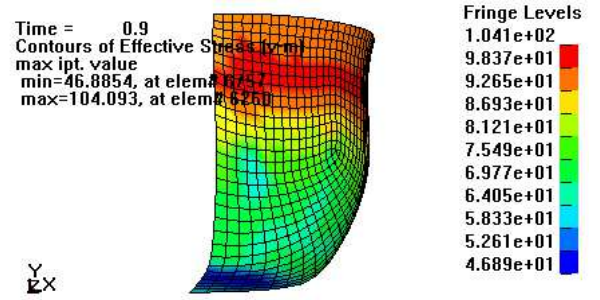

Figure 8: Effective Stress (Von- Mise's) Distribution with $\beta=2.5$ for Trial-1
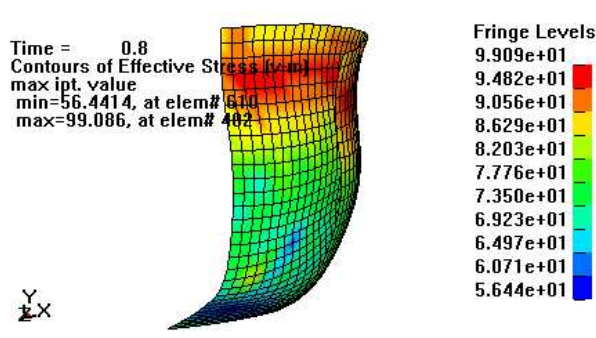

Figure 10: Effective Stress (Von- Mise's ) Distribution with $\beta=2.2$ for trial-1

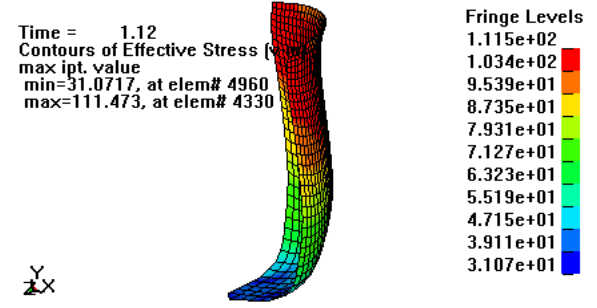

Figure 9: Effective Stress (Von- Mise's) Distribution with $\beta=2$ for Trial-1

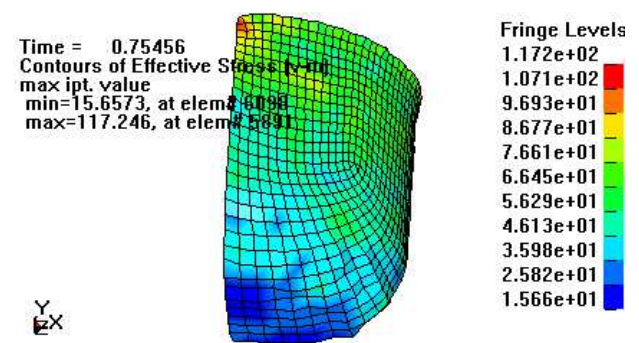

Figure 11: Effective Stress (Von- Mise's ) Distribution with $\beta=2.1$ for trial-1

Table 4: Limit Drawing Ratios for various Trials

\begin{tabular}{|c|c|c|c|c|c|c|}
\hline \multirow{2}{*}{$\begin{array}{c}\text { Trial } \\
\text { No }\end{array}$} & $\begin{array}{c}\text { Column Number } \\
(\mathbf{m m})\end{array}$ & $\begin{array}{c}\mathbf{R}_{\mathbf{d}} \\
(\mathbf{m m})\end{array}$ & $\begin{array}{c}\mathbf{C} \\
\mathbf{\%}\end{array}$ & $\boldsymbol{\mu}$ & $\begin{array}{c}\mathbf{D}_{\mathbf{P}} \\
(\mathbf{m m})\end{array}$ & \multirow{\beta}{*}{$\boldsymbol{\beta}$} \\
\hline $\mathbf{1}$ & 2 & 3 & 7 & 0.015 & 10 & 2.1 \\
\hline $\mathbf{2}$ & 2 & 3 & 20 & 0.45 & 40 & 1.2 \\
\hline $\mathbf{3}$ & 2 & 10 & 7 & 0.45 & 40 & 1.6 \\
\hline $\mathbf{4}$ & 2 & 10 & 20 & 0.015 & 10 & 2.5 \\
\hline $\mathbf{5}$ & 5 & 3 & 7 & 0.45 & 10 & 1.5 \\
\hline $\mathbf{6}$ & 5 & 3 & 20 & 0.015 & 40 & 1.8 \\
\hline $\mathbf{7}$ & 5 & 10 & 7 & 0.015 & 40 & 1.4 \\
\hline $\mathbf{8}$ & 5 & 10 & 20 & 0.45 & 10 & 2.3 \\
\hline S1 & 7.4 & 6.6 & 6.6 & 7.8 & 8.4 & \multirow{2}{*}{} \\
\hline S2 & 7.0 & 7.8 & 7.8 & 6.6 & 6.0 & \\
\hline S1-S2 & 0.4 & -0.8 & -0.8 & 0.8 & 2.4 & \\
\hline
\end{tabular}


From Table 4, it is clear that the cup diameter has a pronounced effect on LDR and the effect of die profile, friction factor and \% clearance is considerable.

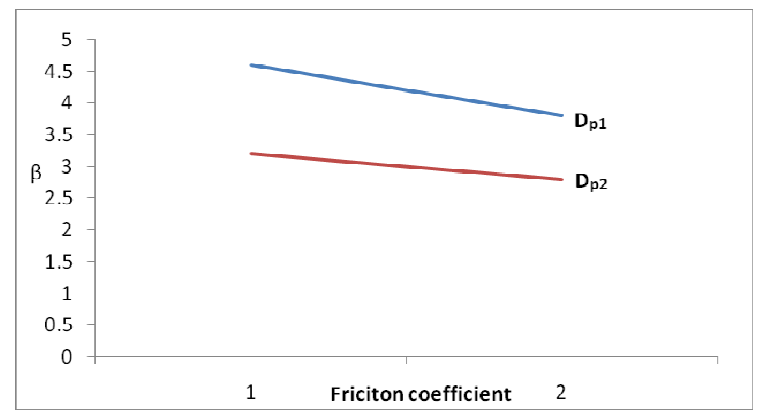

Figure 12: Interaction Graph between Punch Diameter and Friction Factor

Plotting method is used to find out the combined effect of the parameters considered above was taken two at a time. For this each pair of parameters at levels 1-1, 1-2, 2-1, and 2-2 are summed up and plotted as shown in Figures 12 to 16. According to plotting method, higher the difference in slope, higher is the interaction between the two parameters chosen.

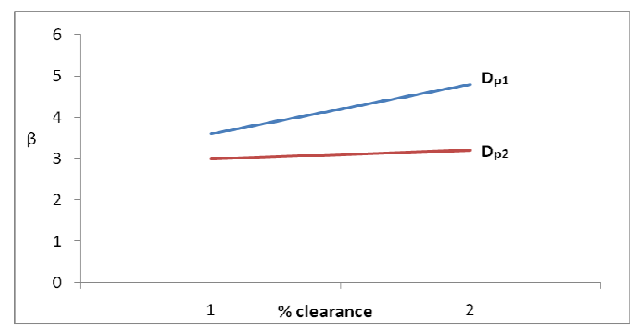

Figure 13: Interaction Graph between Punch Diameter and \% Clearance

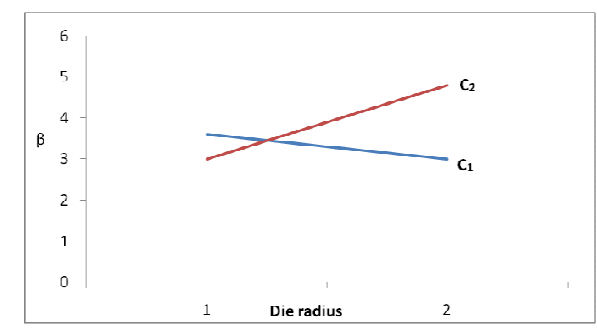

Figure 15: Interaction Graph between Die Profile and \% Clearance

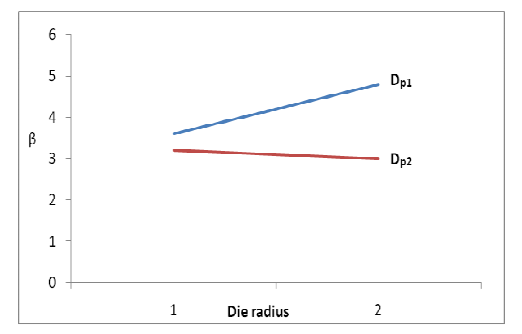

Figure 14: Interaction Graph between Punch Diameter and Die Radius

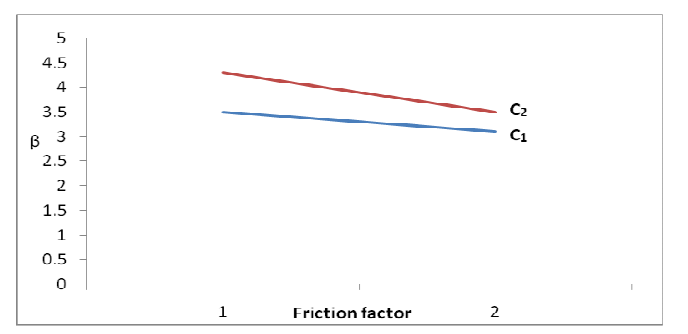

Figure 16: Interaction Graph between Friction Factor and \% Clearance

From the Figure 15, it is evident that there is inter-dependency of die profile and \% clearance in effecting the LDR. There is a little interaction of punch diameter with die profile and \% clearance (Figure 13\& Figure 14). Friction factor independently effect the LDR (from Figure 12 \& Figure 16)

\section{CONCLUSIONS}

The following conclusions are drawn from this work

- The most significant parameter which effect the LDR is punch diameter

- There is a considerable effect of die profile, clearance and friction factor on LDR 
- Variation of the punch profile will not affect the LDR much

- There is a strong interaction of die profile and \% clearance in affecting the LDR

- A little interaction is observed for the punch diameter with die profile and clearance.

- No interactions are found for friction factor.

\section{REFERENCES}

1. A.S.Korhonew, Drawing force in deep drawing of cylindrical cup with flat nosed punch, Journal of Engineering for Industry, Feb'1982, Vol 104 P.29-37.

2. Xi Wang, Jian Cao, On the prediction of side wall wrinkling in sheet metal forming processes, International Journal of Mechanical Sciences 42 (2000) 2369-2394

3. Jamal Hematian, Finite Eiement Modeling of Wrinkling during Deep Drawing of Pressure Vessel End Closures (PVECS), M. S. Thesis, Queen's University Kingston, Ontario, Canada, January 2000

4. Phillip J. Rose, "Taguchi Techniques for Quality Engineering”, 1996, Second edition, McGraw-Hill International.

5. H. Gharib, A.S. Wifi, M. Younan, A. Nassef, Optimization of the blank holder force in cup drawing, Journal of Achievements in materials and manufacturing Engineering. September-October'2006, Vol. 18 Issue 1-2.

6. M.Jurkovic et.al, The Tribological state test in metal forming processes using experiment and modeling, Journal of achievements in materials and manufacturing Engineering., Oct'2006, Vol. 18. Sept-P.383-386

7. J.R.Davis, Concise Metals data Hand book, Table 14.1 
